\title{
SELF-REPORTED PREVALENCE \& ASSOCIATED FACTORS FOR OCCURRENCE OF RECURRENT APHTHOUS STOMATITIS (RAS) IN UNDERGRADUATE MEDICAL \& DENTAL STUDENTS.
}

\author{
Saira Afridi ${ }^{1}$, Jawad Ahmad Kundi ${ }^{1}$, Faisal Hayat ${ }^{1}$
}

1. Sardar Begum Dental College

\begin{abstract}
Background:

Recurrent aphthous stomatitis (RAS) is the most common painful oral lesions that occur frequently in young adults; however the etiology still remains unknown. The present study was conducted to explore the prevalence of RAS in undergraduate medical \& dental students as these are the group who are in their early adulthood and are prone to stress during studies

Materials and Methods:

This was a cross-sectional survey carried out in Gandhara University. Two hundred students of MBBS \& BDS participated in the questionnaire survey. Interview was done through a close-ended questionnaire to report the prevalence of RAS, the associated history, clinical features \& preferred treatment.

\section{Results:}

Prevalence of RAS was found to be $87.5 \%$ in the study population. Most common site was lower lip where $20 \%$ people have ever experienced oral ulcer. Most of the participants $(46 \%)$ tried topical gels and $55 \%$ found the treatment effective. Majority was not sure which medication they used. Approximately half (48\%) of the students associated the ulcer onset with their psychological stress.

\section{Conclusion:}

The prevalence of RAS was found to be alarming (85.7\%) among medical and dental students of Gandhara University. The most common associated factors as experienced and reported by the students were found to be family predisposition and psychological stress.
\end{abstract}

Key words: Medical, Dental, RAS, Stress, Prevalence.

\begin{tabular}{c} 
Correspondence: \\
Dr. Saira Afridi, Sardar Begum Dental College \\
Contact: 0300-9324492, Email: dentistsaira@gmail.com \\
\hline
\end{tabular}

https://doi.org/10.37762/jgmds.1-1.73

\section{INTRODUCTION}

Any erosion in the soft tissue inside the mouth (mucous membrane) is termed as oral ulcer [1]. Oral ulceration starts through a breakthrough in the oral epithelium as a result of which the nerve endings underlying lamina propria are exposed that causes pain or soreness that aggravate with spicy foods and citrus fruits[2]. The most common oral ulcers in the oral mucosa is recurrent aphthous stomatitis (RAS) also known as Canker Sores [1, 3] and about 1 in 5 people have been effected at any stage of life [4] with high prevalence found among females [5]. 
RAS is diagnosed on the basis of history and clinical appearance of the lesion [6]. The lesions are round or ovoid with yellowish base and erythematous halo around it. These are extremely painful and the pain aggravates during eating and speaking [7], thus affecting the quality of life of the patients $[8,9]$. The ulcers are classified as major, minor \& herpetiform $[9,10]$.

The etiology of RAS still remains unclear[5]. Certain factors by which condition may be precipitated or associated may be local which include; local trauma, food, stress, microorganism, any food deficiency or change in hormonal balance. [4] Systemic conditions may play a role in recurrent aphthous ulceration.[11] and psychological stress has been reported as a major contributor in the onset of ulcers [7].

The prevalence of ulcers has been reported to vary from $5-66 \%$ in various nations $[12,13]$. A prevalence of $40 \%$ has been found in a sample of children in United States. [14] Previously a high prevalence rate has been found in the students [15]. However none of the published studies have explored the prevalence of RAS in undergraduate medical \& dental students, therefore the aim of the current study was to find out the self-reported prevalence of RAS among students and also to explore their perception about its predisposing factors.

\section{MATERIALS \& METHODS}

A cross-sectional survey was carried out among the undergraduate medical and dental students $(n=200)$ of Gandhara University. It was done to evaluate the rate of occurrence of RAS among them and to establish its relation with different factors especially stress. This study was approved by the ethical committee and institutional review board of Gandhara University. According to Helsinki declaration,[16] all participants were explained the study details and all their queries were answered to their satisfaction. All participants signed the consent form before the start of the study.

Among the 800 students (both MBBS \& BDS) 200 students were randomly selected as study sample. All students were included in the study and no attempts were made to exclude anyone except those who did not gave consent to participate in the study.

All participants were interviewed a close-ended questionnaire. Besides the age, gender, medical/dental (MBBS/BDS) student and the year in which the participant is, this questionnaire consists of 25 items related to absence or presence of RAS, their recurrence, amount and size of lesion. It also enquired about any treatment/ home remedy done for the aphthous ulcers. Does the therapy effective or not was also asked. Site of ulcers, family

history of the lesion, and daily habits like diet, smoking, tooth brushing were investigated alongwith the clinical features of the lesion.

After gathering all the completed questionnaires from the correspondents, total responses for each item were tabulated. Data was entered and analyzed by using statistical package for social sciences (SPSS) version 19.0. Age was presented as mean standard of deviation. Other variables were presented as frequency and percentages.

\section{RESULTS}

A total of 200 students were interviewed out of which 103 (51.5\%) were MBBS and 97 (48.5\%) were BDS students. Among all participants 175 (87.5\%) of the students had experienced at least one episode of RAS in their life. 
Table 1 highlights the clinical features of oral ulcers as reported by students. When asked about the occurrence of oral ulcers and the amount of time they remained; mostly had experienced oral ulcers in the last month. In $116(58 \%)$ subjects, one ulcer occurred at a

time, the reported duration of healing was mostly few days. Most common site of occurrence of RAS in the study population was lower lip followed by cheek. Among those experiencing oral ulcers $46 \%$ used topical gels as a remedy which proved to be effective in $55 \%$ of the students.

The students who had ulcers were asked about the associated factors that could contribute to RAS. None of the student associated the ulcers with food; the most common associated factor of RAS as reported by the students was family predisposition as $63 \%$ of students had at least one family member with ulcer. The second contributor was reported to be stressful event which was reported by $55 \%$ of the students who had ulcers. The other factors were vigorous tooth brushing $(37.7 \%)$, use of systemic medication prior to ulceration $(36 \%)$, and history of smoking $(27 \%)$.

Table 1: Reported Clinical Features of RAS in undergraduate medical \& dental students.

\begin{tabular}{|c|c|c|c|}
\hline & Category & Number & Percentage \\
\hline \multirow[t]{4}{*}{$\begin{array}{l}\text { When was last time you experienced } \\
\text { oral ulcers? }\end{array}$} & $\begin{array}{l}\text { Experiencing } \\
\text { presently }\end{array}$ & 31 & 15.5 \\
\hline & 1 month & 57 & 28.5 \\
\hline & 6 months & 48 & 24.0 \\
\hline & 1 year & 39 & 19.5 \\
\hline \multirow{4}{*}{$\begin{array}{l}\text { When occur, up to how long oral } \\
\text { ulcers last? }\end{array}$} & Few days & 97 & 48.5 \\
\hline & 1 week & 54 & 27.0 \\
\hline & 2 weeks & 19 & 9.5 \\
\hline & 6 weeks & 5 & 2.5 \\
\hline \multirow{2}{*}{$\begin{array}{l}\text { Number of oral ulcers appearing at a } \\
\text { time? }\end{array}$} & One & 116 & 58.0 \\
\hline & Numerous & 59 & 29.5 \\
\hline \multirow{9}{*}{$\begin{array}{l}\text { In which part of mouth you mostly } \\
\text { experience oral ulcers? }\end{array}$} & Upper lip & 7 & 3.5 \\
\hline & Throat & 3 & 1.5 \\
\hline & Lower gum & 21 & 10.5 \\
\hline & Cheek & 30 & 15.0 \\
\hline & Tongue top & 17 & 8.5 \\
\hline & Lower lip & 40 & 20.0 \\
\hline & $\begin{array}{l}\text { Tongue } \\
\text { underside }\end{array}$ & 8 & 4.0 \\
\hline & Upper gum & 7 & 3.5 \\
\hline & Multiple areas & 42 & 21.0 \\
\hline \multirow[t]{4}{*}{ Any treatment taken for oral ulcers? } & No treatment & 58 & 29.0 \\
\hline & $\begin{array}{l}\text { Vitamins/topical } \\
\text { gels }\end{array}$ & 92 & 46.0 \\
\hline & Home remedy & 25 & 12.5 \\
\hline & Yes & 110 & 55.0 \\
\hline
\end{tabular}




\section{DISCUSSION}

The present study was conducted at Gandhara University to determine the prevalence of RAS in undergraduate medical \& dental students and to explore student experience and perceptions about the ulcer associated factors.

The prevalence of RAS in this study was $87.5 \%$ which was more than the study conducted by Ship JA who, in their study reported a varying prevalence $5 \%$ to $66 \%$ in the general population [17]. The prevalence is also higher from that of Danish dental students (56\%) and Indian dental students (66\%) as well [18] [19]. This can be due to the difference in the medical and dental curricula and the variation in educational environments.

RAS effects the non-keratinized mucosa of the oral cavity that includes soft palate, buccal and labial mucosa, floor of the mouth and ventral surface of the tongue [20]. In the present study lower lip was the most common site of occurrence followed by the cheek mucosa which is in line with the previous reported literature. In a study on Jordanian dental students, Safadi observed that $92 \%$ of the subjects had pain and two third noticed that ulcers lasted for less than a week [5] which is similar to the findings of the present study.

A number of factors have been investigated that either predispose to RAS or are associated with its occurrence. It has been reported that positive family history of RAS may be a causative factor of RAS at an early stage as compared to those having no such history [17]. Current study supports this evidence as two third of the students suffering from RAS had at least one family member suffering from the lesion as well. Psychological stress has been shown to contribute to the onset of ulcers [7] and similar was the finding in present study as half of the students suffering from ulcer reported to have experienced stress before the occurrence of ulcers.

Local trauma is a contributor to RAS which was evident by trauma from vigorous tooth brushing by one third of the students experiencing ulcers. Other factor that was associated with RAS in the present study was smoking. Smoking has been reported to protect from RAS as the mucosa of smokers is thicker [21]. In the current study $27 \%$ of the subjects were smokers but they still had the ulcers. This might be due to the confounding effects of family history and psychological stress.

The study has the limitation of Recall bias of the participants. The clinical features of the ulcers were explained to the participants and the pictures shown however there is a chance of confusing RAS lesions with other type of oral ulcers. However as RAS are the most commonly occurring lesions in this age group therefore the findings are reliable. Future research should focus on comparison of the ulcer and non-ulcer group of students for further validation of current findings.

\section{CONCLUSION}

In the present study, the prevalence of RAS was found to be alarming (85.7\%) among medical and dental students of Gandhara University. The most common associated factors as experienced and reported by the students were found to be family predisposition and psychological stress. 


\section{REFERENCES}

1. Scully, C. and S. Porter, Oral mucosal disease: recurrent aphthous stomatitis. British Journal of Oral and Maxillofacial Surgery, 2008. 46(3): p. 198-206.

2. Scully, C. and D. Felix, Oral Medicine-Update for the dental practitioner Oral malodour. British dental journal, 2005. 199(8).

3. Witman, P.M. and R.S. Rogers III, Pediatric oral medicine. Dermatologic clinics, 2003. 21(1): $p$. 157-170.

4. Natah, S., et al., Recurrent aphthous ulcers today: a review of the growing knowledge. International journal of oral and maxillofacial surgery, 2004. 33(3): p. 221-234.

5. Safadi, R.A., Prevalence of recurrent aphthous ulceration in Jordanian dental patients. BMC Oral Health, 2009. 9(1): p. 31.

6. Weinberg, M.A. and S.L. Segelnick, Management of Common Oral Sores. US Pharm, 2013. 38(6): p. 43-48.

7. Gavic, L., et al., The role of anxiety, depression, and psychological stress on the clinical status of recurrent aphthous stomatitis and oral lichen planus. Journal of Oral Pathology \& Medicine, 2014.

8. $\quad$-, S.C. Aphthous ulcers. Medscape Reference. http://emedicine.medscape.com/article/867080overview. Feb 20, 2014 March 5,2013].

9. RW., B., Treatment strategies for recurrent oral aphthous ulcers. Am J Health Syst Pharm, 2001. 58(1): p. 41-50.

10. Preeti, L., et al., Recurrent aphthous stomatitis. Journal of oral and maxillofacial pathology: JOMFP, 2011. 15(3): p. 252.

11. Rhee, S.-H., Y.-B. Kim, and E.-S. Lee, Comparison of Behcet's disease and recurrent aphthous ulcer according to characteristics of gastrointestinal symptoms. Journal of Korean medical science, 2005. 20(6): p. 971-976.

12. Porter, S., C. Scully, and A. Pedersen, Recurrent aphthous stomatitis. Critical Reviews in Oral Biology \& Medicine, 1998. 9(3): p. 306-321.

13. Davatchi F1, T.-B.A., Jamshidi AR, Chams-Davatchi C, Gholami J, Moradi M, Akhlaghi M, Foroozanfar MH, Barghamdi M, Noorolahzadeh E, Samadi F, Hadj-Aliloo M, Ghaznavi K, Ghaznavi K, Soroosh M, Khabazi A, Salari AH, Sharif SK, Karimifar M, Salessi M, Essalat-Manesh $K$, Nadji A, Shahram F, The prevalence of oral aphthosis in a normal population in Iran: a WHOILAR COPCORD study. Arch Iran Med, 2008. 11(2): p. 207-9.

14. JD., S., Prevalence of oral mucosal lesions in children and youths in the USA. Int J Paediatr Dent, 2005. 15(2): p. 89-97.

15. Ship, I., V. Brightman, and L. Laster, The patient with recurrent aphthous ulcers and the patient with recurrent herpes labialis: a study of two population samples. Journal of the American Dental Association (1939), 1967. 75(3): p. 645-654. 
SELF-REPORTED PREVALENCE \& ASSOCIATED FACTORS FOR OCCURRENCE OF RECURRENT

JGMDS APHTHOUS STOMATITIS (RAS) IN UNDERGRADUATE MEDICAL \& DENTAL STUDENTS

16. Association, W.M., World Medical Association Declaration of Helsinki. Ethical principles for medical research involving human subjects. Bulletin of the World Health Organization, 2001. 79(4): p. 373.

17. Ship, J.A., Recurrent aphthous stomatitis: an update. Oral Surgery, Oral Medicine, Oral Pathology, Oral Radiology, and Endodontology, 1996. 81(2): p. 141-147.

18. Donatsky, O., Epidemiologic study on recurrent aphthous ulcerations among 512 Danish dental students. Community dentistry and oral epidemiology, 1973. 1(1): p. 37-40.

19. PK, P., et al., Association of Recurrent Aphthous Ulcers With Stress Among Students In An Indian Dental Institution. month, 2012. 49: p. 21.6.

20. Schneider, L.C. and A.E. Schneider, Diagnosis of oral ulcers. Mount Sinai Journal of Medicine, 1998. 65: p. 383-387.

21. Tüzün, B., et al., Recurrent aphthous stomatitis and smoking. International journal of dermatology, 2000. 39(5): p. 358-360.

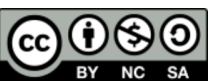

LICENSE: JGMDS publishes its articles under a Creative Commons Attribution Non-Commercial Share-Alike license (CC-BY-NC-SA 4.0). COPYRIGHTS: Authors retain the rights without any restrictions to freely download, print, share and disseminate the article for any lawful purpose. It includes scholarly networks such as Research Gate, Google Scholar, LinkedIn, Academia.edu, Twitter, and other academic or professional networking sites. 